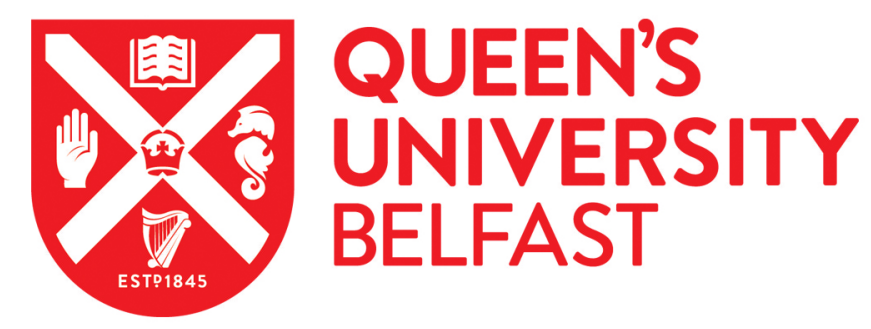

\title{
The future and me: Imagining the future and the future self in adolescent decision making
}

McCue, R., McCormack, T., McElnay, J., Alto, A., \& Feeney, A. (2019). The future and me: Imagining the future and the future self in adolescent decision making. Cognitive Development, 50, 142-156.

https://doi.org/10.1016/j.cogdev.2019.04.001

\section{Published in:}

Cognitive Development

Document Version:

Peer reviewed version

Queen's University Belfast - Research Portal:

Link to publication record in Queen's University Belfast Research Portal

\section{Publisher rights}

Copyright 2019 Elsevier

This manuscript is distributed under a Creative Commons Attribution-NonCommercial-NoDerivs License

(https://creativecommons.org/licenses/by-nc-nd/4.0/), which permits distribution and reproduction for non-commercial purposes, provided the author and source are cited.

\section{General rights}

Copyright for the publications made accessible via the Queen's University Belfast Research Portal is retained by the author(s) and / or other copyright owners and it is a condition of accessing these publications that users recognise and abide by the legal requirements associated with these rights.

Take down policy

The Research Portal is Queen's institutional repository that provides access to Queen's research output. Every effort has been made to ensure that content in the Research Portal does not infringe any person's rights, or applicable UK laws. If you discover content in the Research Portal that you believe breaches copyright or violates any law, please contact openaccess@qub.ac.uk. 
The future and me: Imagining the future and the future self in adolescent decision making

Robyn McCue $^{1}$, Teresa McCormack ${ }^{1}$, James McElnay ${ }^{1}$, Alix Alto $^{2}$ and Aidan Feeney ${ }^{1}$

1. Queen's University Belfast

2. University of Massachusetts Amherst

Author Note

Robyn McCue, Teresa McCormack, James McElnay, Aidan Feeney, School of Psychology, Queen's University Belfast; Alix Alto, Department of Psychological and Brain Sciences, University of Massachusetts Amherst. The authors have no declarations of interest. The data reported in this paper were collected by Robyn McCue for a $\mathrm{PhD}$ dissertation supervised by Aidan Feeney, Teresa McCormack and James McElnay. Robyn McCue gratefully acknowledges the support of a studentship from the Department for the Economy, Northern Ireland.

Please address correspondence about this article to Robyn McCue, School of Psychology, Queen's University Belfast, University Road, Belfast BT7 1NN, Northern Ireland. E-mail: rmccue01@qub.ac.uk 


\begin{abstract}
Feeling connected to one's future self and imagining one's personal future (Episodic Future Thinking, EFT), are known to attenuate short-sighted decision making in adults. Less is known about how these constructs overlap, or how they relate to impulsivity in adolescents. This study investigated how future self-connectedness, EFT and a number of other futureoriented constructs relate to one another and to the tendency to discount the future. 175 adolescents (11 - 18 years) completed measures of EFT, future self-connectedness, time attitudes, temporal focus, depressive symptomatology and temporal discounting. EFT and future self-connectedness were significantly correlated, indicating adolescents who felt connected to their future selves imagined the future with greater episodic richness. EFT and future self-connectedness independently predicted discounting. Weak associations between the future-oriented constructs, and their differential relations with discounting, indicate these measures assess distinct, but loosely related temporal constructs. Results suggest that combined interventions may improve future-oriented decision making in adolescents.
\end{abstract}

Keywords: Future self-connectedness; Episodic Future Thinking; Temporal Discounting; Impulsivity; Adolescence 


\section{The future and me: Imagining the future and the future self in adolescent decision}

\section{making}

The ability to think about the future starts to emerge early in development and plays a key role in decision making throughout the lifespan (Steinberg et al., 2009; Stoddard et al., 2011; Suddendorf \& Busby, 2005). However, thinking about the future is argued to be especially pertinent during adolescence, on the assumption that the primary function of this developmental stage is to prepare for adulthood (Nurmi, 1991). For a successful transition to adulthood, it is crucial for adolescents to integrate their thoughts of the future with their present, in order to set goals and make decisions that have the power to influence important opportunities in later life (Nurmi, 1991). Failure to actively think about and plan ahead for the future is associated with a number of negative outcomes for adolescents, including school failure, delinquency, high rates of substance abuse, and early onset of sexual activity (Chen \& Vazsonyi, 2013; Kerpelman \& Mosher, 2004; McKay, Percy, \& Cole, 2013; Nurmi, 1991; Robbins \& Bryan, 2004; Seginer, 2003, 2009; So, Voisin, Burnside, \& Gaylord-Harden, 2016). Thus, adolescence is a period of specific interest in the study of future-oriented cognition.

How people think about the future has been conceptualized and studied in a variety of ways, ranging from how often they think about it and the attitudes they have towards it, to the goals and aspirations they establish for themselves and how capable they are of foregoing short-term gratification in order to achieve these goals. These different approaches have captured the attention of researchers from across multiple domains of psychology. For example, decision making researchers and behavioral economists have extensively explored how people decide to discount future rewards in favour of more immediate gratification (Frederick, Loewenstein, \& O'Donoghue, 2002; Soman et al., 2005), and have found that feeling connected to one's future self has an influence on decisions and behaviors that 
concern the future (Bartels \& Rips, 2010; Bartels \& Urminsky, 2011; Hershfield, Tess Garton, Ballard, Samanez-Larkin, \& Knutson, 2009; Hershfield, 2011; Urminsky, 2017; van Gelder, Hershfield, \& Nordgren, 2013). At the same time, cognitive psychologists have begun to focus on the construct of episodic future thinking, generally conceived of as the ability to “pre-experience” specific future personal events (Atance \& O’Neill, 2001; Michaelian, Klein, \& Szpunar, 2016). There is also a rich tradition of research that has established the role played by individual differences in people's attitudes toward the future, and their tendencies to think often, or not at all, about the future, in shaping present behavior (Mello, Worrell, \& Andretta, 2009; Shipp, Edwards, \& Lambert, 2009; Zimbardo \& Boyd, 1999). One of the key aims of the study described in this paper was to draw together these diverse lines of research in a developmental context by examining relations between these different aspects of future thinking in adolescence. We outline below how each of these lines of research have examined future cognition, before describing our study.

\section{Temporal discounting and future thinking}

One reason that researchers are particularly interested in future-oriented cognition in adolescence is that historically adolescence has been characterized by a heightened proclivity for short-sighted, impulsive, and at times dangerous behavior (Arnett, 1996; Steinberg, 2004). The discounting of future rewards (Ainslie, 1974; Madden \& Bickel, 2010) is widely considered to contribute to myopic decision making. Temporal discounting is typically assessed using intertemporal choice tasks in which a participant is asked to choose between a small, immediate reward (e.g. \$80) and a larger, delayed reward (e.g. \$100 in 2 weeks), and is generally considered a reliable correlate of impulsivity (Bickel \& Marsch, 2001). Steep discount rates (i.e., heavily discounting the value of future rewards) are associated with an array of negative health and problem behaviors in both adults and adolescents, including substance use (Audrain-McGovern et al., 2009; Khurana, Romer, Betancourt, \& Hurt, 2018; 
Kim-Spoon, McCullough, Bickel, Farley, \& Longo, 2015; Wang, Capous, Koh, \& Hou, 2014) and gambling (Cosenza \& Nigro, 2015). Discounting rates are higher in early to midadolescence and then decline into adulthood (Banich et al., 2013; Christakou, Brammer, \& Rubia, 2011; Khurana et al., 2018; Steinberg et al., 2009; van den Bos, Rodriguez, Schweitzer, \& McClure, 2015), although Khurana et al.'s (2018) longitudinal study has demonstrated that there are sub-populations of adolescents who show different developmental trajectories regarding delay discounting, and that it is adolescents who show consistently high discounting rates from early adolescence onwards that are likely to subsequently engage in risky behavior.

The role of future-oriented cognition in determining discount rates has attracted much recent interest in this area of intertemporal decision making. Specifically, two factors that have been found to be related to discount rates are episodic future thinking (Benoit, Gilbert, \& Burgess, 2011; Bulley, Henry, \& Suddendorf, 2016; Peters \& Büchel, 2010) and future self-connectedness (Bartels \& Rips, 2010; Bartels \& Urminsky, 2011), also referred to in the literature as future self-continuity (Hershfield, 2011).

Episodic future thinking. Episodic future thinking (EFT), or prospection (Gilbert \& Wilson, 2007) is closely linked to episodic memory (Atance \& O’Neill, 2001; Schacter, Addis, \& Buckner, 2008). Just as episodic memory involves the re-experiencing of an autobiographical event that has occurred in the past, EFT involves the pre-experiencing of an autobiographical event that might occur in the future, achieved through mental simulation (Suddendorf \& Corballis, 2007; Szpunar, 2010; Tulving, 2005).

Researchers have suggested that this capacity to construct detailed simulations of the future helps support future-oriented decision making by yielding previews of the emotional significance of delayed rewards (Benoit et al., 2011; Boyer, 2008), impeding us from discounting their value, and thus countering the tendency to show an impulsive preference for 
immediate rewards (Bar, Bartlett, Noe, \& Schank, 2009). Studies have found evidence supporting this notion, showing that engaging in EFT during intertemporal choices can attenuate temporal discounting in adults (Benoit et al., 2011; Daniel, Stanton, \& Epstein, 2013; Peters \& Büchel, 2010). Evidence to support a link between EFT and intertemporal choice has also been found in studies of adolescents. Bromberg, Wiehler, and Peters (2015) measured EFT skills in adolescents alongside their tendency to discount future rewards, and found that the former measure predicted discounting behavior even when controlling for variables such as episodic memory skills. Moreover, Bromberg, Lobatcheva, and Peters (2017) found that, as in adults, engaging in EFT reduced temporal discounting in an adolescent sample. Both of these studies provide initial support for the idea that EFT and the tendency to defer gratification are linked in adolescence.

Future self-connectedness. The extent to which someone discounts future rewards has also been found to vary depending on the degree to which they feel their present self is connected, or similar, to their future self (Bartels \& Rips, 2010; Bartels \& Urminsky, 2011; Urminsky, 2017). Individuals who rate their present self as being highly connected to their future self are less likely to discount delayed rewards in intertemporal choice tasks and more likely to save money across their lifespan (Bartels \& Rips, 2010; Bartels \& Urminsky, 2011; Hershfield, Tess Garton, et al., 2009; Urminsky, 2017). Researchers in this area suggest that when the future self is seen as disconnected from, or dissimilar to, the present self, it is perceived almost as if it were a different person (Hershfield, Wimmer, \& Knutson, 2009; Hershfield, 2011). As a result, people tend to be less motivated to make decisions that will benefit their future self, and more likely to make seemingly irrational and short-sighted decisions that benefit their present self (Hershfield, 2011).

It has been argued that periods of transition like adolescence can lead to the anticipation of personal change, resulting in the present self feeling more disconnected from 
the future self (Bartels \& Rips, 2010). Consequently, adolescents may be especially vulnerable to making short-sighted decisions that benefit their present self even at a time when it is important to be considering the needs and desires of their future self (Nurmi, 1991). Accordingly, future self-connectedness may be an important construct for understanding adolescent impulsive behavior. However, no studies to date have examined how future self-connectedness is related to intertemporal choice and other aspects of futureoriented cognition in adolescents.

\section{Measuring individual differences in temporal focus and time attitudes}

Work on future thinking in the individual differences tradition has revealed that although people are capable of shifting their attention between different time periods depending on situational context, they tend to preferentially attend to certain time periods over others (Holman \& Silver, 1998; Shipp et al., 2009; Zimbardo \& Boyd, 1999). The extent to which people characteristically devote their attention to thoughts of their past, present and future has been referred to as both temporal orientation (Holman \& Silver, 1998; Zimbardo \& Boyd, 1999) and temporal focus (Shipp et al., 2009). Future orientation, defined by Zimbardo and Boyd (1999) as a cognitive bias toward the future, is associated positively with educational achievement (Mello \& Worrell, 2006), and negatively with risky behaviors such as substance use (Apostolidis, Fieulaine, \& Soulé, 2006; Barnett et al., 2013). However, measures of temporal orientation, such as the Zimbardo Time Perspective Inventory (Zimbardo \& Boyd, 1999) and the Time Orientation Scale (Holman \& Silver, 1998) often integrate items assessing temporal focus with items assessing temporal attitudes and other individual differences constructs such as conscientiousness. Shipp et al. (2009) argued that it may be beneficial to use measures that separate out the amount of time spent thinking about specific time periods from one's attitudes and feelings about such periods. To this end, they developed the Temporal Focus Scale (TFS) to assess only levels of cognitive engagement 
with the past, present and future, with high levels of future temporal focus being associated with life satisfaction, optimism and risk-taking in adults (Busseri, Malinowski, \& Choma, 2013; Shipp et al., 2009), and life satisfaction, career efficacy and self-esteem in adolescents (Chishima, McKay, \& Cole, 2017; Chishima, McKay, \& Murakami, 2017).

While the TFS is intended to purely assess levels of cognitive engagement with the future, it is possible to assess adolescent's affective evaluations of the future using measures such as the Adolescent Time Attitude Scale (ATI-TA, Worrell \& Mello, 2007). Time attitude consists of an individual's emotions and evaluative feelings toward the past, present and future (Mello et al., 2009). Attitudes toward the future are a frequently measured dimension of future-oriented cognition, and overlap somewhat with concepts such as optimism, pessimism, and hope (Johnson, Blum, \& Cheng, 2014). Overall, in adolescents, positive attitudes toward the future are associated with psychological wellbeing (Andretta, Worrell, \& Mello, 2014) and educational attainment (Adelabu, 2008; Andretta et al., 2014), in addition to lower levels of substance abuse and risk taking (Robbins \& Bryan, 2004). There is some evidence that temporal focus and time attitudes overlap in that people generally prefer to think about the time periods for which they have positive attitudes (Shipp et al., 2009).

\section{Future Orientation: A single construct?}

Within the individual differences literature, individuals with positive attitudes toward the future or those who think often about the future are often referred to as 'future-oriented' (Robbins \& Bryan, 2004; Zimbardo \& Boyd, 1999). However, willingness to wait for delayed rewards during temporal discounting tasks could also be taken as an indication of a future-oriented individual (Steinberg et al., 2009). Furthermore, feeling connected to one's future self and being capable of vividly imagining future episodes might also be characteristic of an orientation towards the future. That is, looking across the literature on future thinking, there are a number of different ways in which one might operationalize the notion of future 
orientation. Although one might assume these various measures relate to one another, there is surprisingly little work exploring how different measures of future orientation overlap, and rather mixed findings from those studies that have included more than one measure. Some studies with both adolescents and adults have found that measures of future orientation derived from Zimbardo’s Time Perspective Inventory are at least modestly correlated with delay discounting (Daugherty \& Brase, 2010; Göllner, Ballhausen, Kliegel, \& Forstmeier, 2018; Guo, Chen, \& Feng, 2017; van den Bos et al., 2015, though see Baumann \& Odum, 2012). However, one recent study with adults suggests that questionnaire-based measures of future-orientation themselves are only weakly related (and are differentially related to health outcomes; McKay, Perry, Cole, \& Worrell, 2018).

Turning to EFT, there are mixed findings regarding links between questionnairebased measures of future orientation and aspects of EFT. While Arnold, McDermott, \& Szpunar, (2011) found that future orientation, as measured by the Zimbardo Time Perspective Inventory, predicted the degree to which participants reported a sense of "pre-experiencing" future events, D’Argembeau, Ortoleva, Jumentier, \& Van Der Linden, (2010) did not find this relation, although they did find a selective correlation between future orientation and the number of sensory details individuals reported about imagined future events.

As we have pointed out above, both EFT and future self-connectedness have been linked to future-oriented decision making, as measured by intertemporal choice tasks (Bartels \& Rips, 2010; Bromberg et al., 2015; Hershfield et al., 2011). However, it is not clear how these two factors may be interrelated. Indeed, as Hershfield and Bartels (2018) have pointed out, as yet we know relatively little about what determines future self-connectedness. Hershfield and Bartels (2018) suggest that future self-connectedness may be at least in part determined by how vividly individuals imagine the future. However, they also speculate that vividly imagining one's future might facilitate delayed gratification even if it does not affect 
levels of future self-connectedness. In fact, to the best of our knowledge, the roles of EFT and future self-connectedness in temporal discounting have never been examined in the same study, thus it is unknown whether EFT and future self-connectedness have independent or overlapping relations with temporal discounting.

In order to examine whether the discussed measures of future thinking reflect, to some degree at least, the operation of a single underlying characteristic, the study will examine how future temporal focus and future time attitudes relate to EFT, future self-connectedness and temporal discounting in adolescents. The study also included one additional measure that we have not yet discussed, which was a measure of depression. We included this measure because future-oriented cognition has been shown to relate to psychopathology and wellbeing (MacLeod, 2017). Depression has been specifically linked with impaired episodic memory and EFT (Roepke \& Seligman, 2016; Williams et al., 1996), with depressed individuals showing a tendency to remember past events and imagine future events that are less specific in nature, a phenomenon referred to as over-general memory and over-general future thinking (Williams et al., 1996; Williams et al., 2007). Moreover, depressive symptomatology is also known to be associated with a tendency to discount future rewards (Jarmolowicz et al., 2014; Pulcu et al., 2014). Because of what is known about the relationship between depression, EFT, and temporal discounting, we controlled for depression when evaluating the role of EFT in adolescents' delay discounting in this study. This also provided the opportunity to examine relations between adolescent depression and all the elements of future-oriented cognition discussed so far.

Knowledge about the relations between depression, future self-connectedness, temporal focus and time attitudes in adolescents is limited. Although future selfconnectedness and temporal focus relate to depressive symptoms in adults (McKay, Cole, \& Percy, 2017; Sokol \& Eisenheim, 2016), this association has yet to be replicated in 
adolescents, and while scores on the Adolescent Time Attitude Scale have been linked with self-esteem and self-efficacy (McKay, Percy, Cole, Worrell, \& Andretta, 2016; Mello et al., 2009), it is unknown how scores on this scale specifically overlap with depressed mood in adolescents. Elucidating how depression influences or is influenced by future-oriented cognition in adolescents is of interest given that, and that impaired future-oriented cognition might contribute to impaired decision-making, planning and self-regulation (Roepke \& Seligman, 2016; Taylor, Pham, Rivkin, \& Armor, 1998), which is likely to be detrimental to adolescents' development.

\section{Study Overview}

This study of adolescents included existing questionnaire measures of temporal focus (TFS, Shipp et al., 2009) and time attitudes (ATI-TA, Mello \& Worrell, 2007), as well as a measure of future self-connectedness (adapted from Bartels \& Rips, 2010, and Hershfield et al., 2011) and of delay discounting (Green, Myerson, \& Ostaszewski, 1999). We also assessed EFT by using a task in which participants had to generate written descriptions of future events; this task also measured episodic memory so that we could examine the selectivity of any relations between the other measures of future orientation and EFT by controlling for episodic memory skills. The study allowed us for the first time to examine how EFT and future selfconnectedness relate to one another, and also whether these measures independently predict variance in adolescent's tendency to discount future rewards in an intertemporal choice task. Finally, we included a measure of depression (Center for Epidemiologic Studies Depression Scale, CES-D, Radloff, 1977) in order to explore how the future thinking measures relate to psychopathology in adolescents, given that depressive symptomatology has been linked with impaired abilities to imagine and make decisions about the future. 


\section{Method}

\section{Participants}

One hundred and seventy five (61.7\% female) adolescent participants aged 11.7 to 18.5 years $(M=14.75, S D=1.84)$ were recruited from five schools in the region of the UK local to the authors' university. All participants aged under 16 years of age were required to provide parental or guardian consent in order to take part. The study received ethical approval from the Research Ethics Committee of the psychology department in the authors' university. In terms of age distribution, $43 \%$ of adolescents in the sample were 13 and younger, $39 \%$ were aged 14 to 16 and $17 \%$ were aged 17 and over. Participants were tested in groups in their schools.

\section{Measures}

Temporal Discounting (TD) Task. This was based on the task used by Green et al. (1999). Participants were asked to make repeated choices between a large constant reward (£100; UK pounds) available after a delay (Tomorrow, day after tomorrow, 1 week, 2 weeks, 2 months, 6 months and 1 year) and a smaller reward (of 12 values ranging from $£ 5$ to $£ 96$ ) available immediately. These choices were hypothetical, i.e., participants did not receive any reward based on their choices. Each of the 7 delays was paired once with every immediate reward resulting in 84 choices. For each participant, the smaller reward was presented in ascending order, while the delay to the larger reward was randomized. Subjective values of the delayed reward were determined in order to calculate the area under the curve (AUC; Meyerson et al., 2001).

Discounting data pre-processing. The subjective value of the delayed reward for each delay was calculated by determining the participant's switch point; that is, the point at which the participant's preference for the larger, delayed reward (typically when the value of the immediate reward is small) switched to a preference for the smaller, immediate reward 
(typically when the value of the immediate reward is larger). Operationally, this was taken as the midpoint between the smallest value of immediate reward accepted and the largest value that was rejected (Mitchell \& Wilson, 2010). Subjective values and delays were then normalized following the process outlined by Myerson, Green, \& Warusawitharana, (2001). First, subjective values were expressed as proportions of the amount of the maximum delayed reward (i.e., the participant's subjective value at each delay was divided by 100 ), and delays were expressed as proportions of the maximum delay. These normalized values were then used as $\mathrm{x}$ and $\mathrm{y}$ coordinates, with delay on the $\mathrm{x}$ axis and subjective value on the $\mathrm{y}$ axis. Vertical lines were then drawn from each data point on the $\mathrm{x}$ axis to create seven trapezoids. Using the formula $(\mathrm{x} 2-\mathrm{x} 1) *[(\mathrm{y} 1+\mathrm{y} 2) / 2]$, where $\mathrm{x} 1$ and $\mathrm{x} 2$ are successive delays and $\mathrm{y} 1$ and y2 are the subjective values associated with these delays, the areas of the seven trapezoids were calculated. When summed, this gives the total area under the curve (AUC). As values were normalized, the AUC ranged from 0 to 1 meaning the smaller the AUC, the steeper the participants' discounting function.

Episodic Future Thinking - Remember/Imagine task. Participants' episodic past (EPT) and future thinking (EFT) was assessed in a task using a pen-paper format (see also Arnold et al., 2011). The task was adapted from the Child Autobiographical Interview (Willoughby, Desrocher, Levine, \& Rovet, 2012), which itself is adapted from the Autobiographical Memory Interview (Levine, Svoboda, Hay, Winocur, \& Moscovitch, 2002). Participants were asked to remember two past events, one which occurred 3 months ago (near) and one which occurred 1 year ago (distant). They were also asked to imagine two future events, one which might occur in 3 months and one which might occur in 1 year. All participants were first asked to describe a past event that occurred 3 months ago and a future event that might occur in 3 months. The order of the third and fourth event (past/future or future/past) was counterbalanced across participants (see Gott \& Lah, 2014). 
At the beginning of the task, participants were provided with an example list of autobiographical events (e.g., a specific birthday party, an event that occurred on holiday, graduation etc.), but were instructed, both verbally by the researcher and written on the test booklet, that they could describe any event, even if it was not present on the list. Participants were explicitly asked to describe specific events, meaning that (a) they had to be personally involved in the event, (b) the event was specific to a time and place, and (c) the event occurred over no more than one day. They were also verbally instructed that future events were to be novel. Participants were also provided with an example of an event that would be appropriate (a day spent at Disneyland Paris) and an example of an event that would not be appropriate (a two-week holiday in France). Participants had three minutes to describe their event by writing down as much detail as possible about what they remembered/imagined. This was then followed by a general verbal probe provided by the tester ('Is there anything else you can tell me about that event?').

Scoring of the Remember/Imagine task. Participants' four event narratives were assessed using the Autobiographical Memory Interview Scoring Manual (Levine et al., 2002). The written text was segmented into two main categories of details: internal (episodic) and external details (non-episodic). Details were categorized as internal if they were directly related to the event described, were specific in time and place, and conveyed a sense of episodic re/pre-experiencing. Details that did not fit these specifications were categorized as external.

Internal details were then assigned to one of five episodic detail subcategories: a) event; b) place; c) time; d) perceptual; and e) emotion or thought. External details were assigned to one of four subcategories: a) semantic fact; b) repetition; c) metacognitive statements; and d) events that occurred outside of the main event described. Compound scores for internal and external scores were calculated by averaging over these subcategories. 
Each described event was also assigned a qualitative experimenter rating assessing the episodic richness of the description on a scale of 0 to 6 . This rating was used as a measure of the extent to which the description evoked an impression of re/pre-experiencing by taking the reader back to a specific moment in time and place in which they are able to re-create the perceptual, emotional and cognitive contextual detail of the event.

All event narratives were scored first by the researcher and then by a second, independent rater for reliability. Intraclass correlations (ICC; two-way mixed effects model) were calculated to examine the covariance and agreement between raters (Portney \& Watkins, 2000). ICCs were high for past internal details $(\mathrm{ICC}=.94, p<.001)$, future internal details $(\mathrm{ICC}=.86, p<.001)$, past external details $(\mathrm{ICC}=.84, p<.001)$, future external details $(\mathrm{ICC}=.84, p<.001)$, and future episodic richness $(\mathrm{ICC}=.85, p<.001)$, and only slightly lower for past episodic richness $(\mathrm{ICC}=.80, p<.001)$. The internal details provided by participants and their episodic richness ratings were highly correlated $\left(\mathrm{r}_{(160)}=.91, p<.001\right.$ for future event narratives and $\mathrm{r}_{(160)}=.86, p<.001$ for past narratives). Therefore, these two measures were combined using z-scores to give an overall episodic rating for past and future event narratives, yielding the EPT and EFT episodic measures respectively.

Phenomenological rating scales. After having described each event, participants assessed the phenomenal characteristics of the remembered/imagined event using a series of rating scales (adapted from D’Argembeau \& Van der Linden, 2006). Participants were asked about the extent to which visual and other sensory details (sound and smell) were clear $(1=$ not at all, 7 = completely). The clarity of the location and time in which the remembered/imagined event took place was also assessed $(1=$ not at all, $7=$ extremely clear $)$. Participants also rated their feeling of re-experiencing/pre-experiencing the event $(1=$ not at all, $7=$ completely) and sense of mentally travelling to the time when the event happened/would happen $(1=$ not at all, $7=$ completely $)$. Three items assessed the emotional 
content of the remembered/imagined event: participants rated their feeling of reexperiencing/pre-experiencing the emotions associated with the event $(1=$ not at all, $7=$ completely), the valence of the event $(-3=$ very negative, $+3=$ very positive $)$ and the emotional intensity of the event $(1=$ not strong, $7=$ very strong $)$. A final rating scale assessed the feeling of subjective distance to the event $(1=$ quite far away, $10=$ very far away $)$. Participants provided these ratings for each event they described.

Phenomenal characteristic composites. For each event, participants' ratings of sensory (visual, sound, smell), temporal, and locational clarity were summed to create a composite score labelled clarity. Participants' ratings of re-experiencing/pre-experiencing the event and ratings of mentally travelling backward/forward in time to when the event happened/would happen were summed to create a composite labelled mental time travel. Participants' ratings of re-experiencing/pre-experiencing the emotions associated with the event were analysed as a separate variable, as were ratings of emotional intensity, emotional valence and temporal distance. Final past and future variables were calculated by averaging across the near/distant conditions. Table 1 gives an overview of the EPT and EFT phenomenal variables and their associated items.

Future self-connectedness. A measure of future self-connectedness was adapted from Bartels and Rips (2010) and Hershfield et al., (2011). Participants were asked to think of the person they are now (the present self) and the person they think they will be in 5 years (the future self) and to rate, on a horizontal scale of $0-100$, how similar they feel their present self and future self to be in terms of 4 dimensions: personality, hobbies, likes-dislikes, and overall. The scale was verbally and pictorially anchored at either end by two circles representing the present and future self that overlap to different degrees (not overlapping to almost completely overlapping) and by the labels 'completely different' to 'exactly the 
same'. Cronbach's alpha across the 4 dimensions indicated moderate internal consistency $(\alpha$ $=.64)$. For the purposes of analysis, an average of the four dimensions was taken.

Table 1. A summary of EFT and EPT phenomenal variables and the items associated with them

\begin{tabular}{ll}
\hline Variable name & Item(s) \\
\hline Clarity & Sum of five items assessing visual clarity, clarity of \\
& sound and smell, and temporal and locational clarity of \\
& the remembered/imagined event. \\
& Sum of two items assessing extent to which the \\
& participant re-experienced/pre-experienced the event \\
Mental Time Travel (MTT) & and the extent to which participant felt they travelled \\
& backward/forward in time to when the event \\
& happened/would happen. \\
& One item assessing the extent to which participants felt \\
& they re-experienced the emotions that had \\
happened/pre-experienced the emotions that would & happen, as they remembered/imagined the event. \\
Emotional re-experiencing / pre- & One item assessing the strength of the emotions the \\
experiencing & participant felt as they remembered/imagined the \\
event. & One item assessing whether the remembered/imagined \\
event was positive or negative. \\
One item assessing how distant the \\
remember/imagined event felt (subjectively) to the \\
participant. \\
Emotional Valence
\end{tabular}

Temporal Focus Scale (TFS). The TFS (Shipp et al., 2009) is a 12-item scale consisting of three four-item subscales assessing an individual's degree of cognitive engagement with the past, present and future. Scores on each subscale are summed and divided by 4 to give an average score for that subscale. Past and future temporal focus subscales had internal consistency estimates greater than .78. However, present temporal 
focus was less internally consistent $(\alpha=.56)$. This contrasts with the reliability estimates reported by Shipp et al., (2009), who found Cronbach's alpha ranged from .74 to .89, but is more similar to those reported by McKay, Percy, Goudie, Sumnall, \& Cole, (2012), who also found low reliability estimates for the TFS present subscale.

Adolescent Time Inventory - Time Attitudes (ATI-TA). The ATI-TA (Mello \& Worrell, 2007) is a 30-item scale consisting of six five-item subscales (past negative/ positive, present negative/positive and future negative/positive) designed to assess how adolescents feel about the past, present and future. Typically, scores on each subscale are summed and divided by 5 to give an average score for that subscale. For the purposes of this study, the negative subscale items for each time period were reverse scored. These reverse scored items were then summed alongside the positive subscale items for each corresponding time period, and a mean calculated by dividing by 10 . These three scales were labelled 'past positivity', 'present positivity' and 'future positivity'. Internal consistency estimates for the three ATI-TA positivity subscales ranged from .89 to .93 . This is consistent with previous studies that have reported Cronbach's alpha to range from .70 to .90 (Andretta, Worrell, Mello, Dixson, \& Baik, 2013; McKay et al., 2016).

Center for Epidemiologic Studies Depression Scale (CES-D). The CES-D (Radloff, 1977) is a 20-item validated scale used to measure depressive symptoms in the general population. Cronbach's alpha indicated good internal consistency $(\alpha=.92)$. This is consistent with reliability estimates reported by other studies using this measure in an adolescent sample (e.g., Kelly, Becker, \& Spirito, 2017; Yang, Jia, \& Qin, 2015)

\section{Procedure}

Schools were invited to take part in the study by letter which linked to a promotional video that outlined the purpose and nature of the study. Five schools in total agreed to take part. 
Schools that agreed to take part were provided with parental information sheets and consent forms prior to data collection.

Data was collected in classroom settings by the same researcher. Parental consent forms were collected from participants younger than 16 years on the day of testing. Written informed assent was then obtained from participants under the age of 16 years. Written informed consent was obtained from participants aged 16 years and over. Two questionnaire booklets were then distributed, the first of which contained the measure of future selfconnectedness, ATI-TA, TFS and the CES-D, and the second of which contained the temporal discounting task. Participants were instructed to complete the booklets in this order. Once the researcher had ascertained all participants were finished, a third booklet containing the Remember/Imagine task was distributed. This task was facilitated by the researcher, who read aloud the instructions on the front page. Participants were then timed for 3 minutes as they wrote, after which they were verbally prompted by the researcher. The researcher then waited for the participants to complete the accompanying phenomenological rating scales. Once finished, the timer was reset, and the participants were asked to move on to the next event. Following this final task, the booklets were collected, and participants were provided with a debrief sheet that the researcher read aloud.

\section{Results}

\section{Data pre-processing}

Missing or unsystematic data \& outlier removal. Fifteen adolescents failed to complete one or more of the written narratives and/or their associated rating scales and so were excluded from any analysis involving EPT or EFT variables.

Temporal discounting data from eleven participants was identified as non-systematic using a procedure outlined by Johnson and Bickel (2008), and so were excluded from 
analysis. Data was deemed non-systematic if any subjective value (of the delayed reward) was larger than the subjective value associated with the previous, shorter delay by a magnitude greater than $20 \%$ of the delayed reward (£20), or if the subjective value associated with the final delay (1 year) was not less than the subjective value associated with the first delay ( 1 day) by at least $10 \%$ of the later reward (£10). Non-systematic patterns may occur due to the participant changing response strategy during the task, a lack of attention on the task, or specific time points being associated with a need for money in the participant's real context, such as a birthday party (Wilson, Mitchell, Musser, Schmitt, \& Nigg, 2011).

Three participants were identified as scoring more than $3 S D$ above the mean on the CES-D. Of the TFS and ATI-TA scores, one future temporal focus score, one future positivity score and two past positivity scores were identified as being more than $3 S D$ below the mean. Of the phenomenological ratings, two future valence ratings and one past intensity rating were more than $3 S D$ below the mean. These scores were excluded from subsequent analysis.

Transformations. AUC and depression scores were both highly positively skewed as determined by skewness z-scores $>4$. Square root transformations reduced AUC and depression skewness $z$-scores to $<2$. Of the phenomenological rating variables, 5 were negatively skewed. Square transformations reduced the skewness z-scores of mean past mental time travel, mean past re-experiencing, mean past valence, mean past intensity, and mean future intensity ratings to $<2$. Of the EPT and EFT scores provided by raters, both past and future external detail scores were positively skewed. Square root transformations reduced the skewness $z$-scores of these scores from $>4$ to $<1.5$. These transformed variables were used for the purposes of analysis.

Descriptive Statistics. Descriptive statistics for the key variables used in the following correlation and regression analyses are summarised in Table 2. 
Future self-connectedness, EFT and discounting. To explore the relationships between the measures of connectedness to the future self, EFT and temporal discounting, a series of partial correlations controlling for age were conducted to address a series of questions. These were followed by a hierarchical regression analysis.

Table 2. Means, standard deviations, medians and range for key variables

\begin{tabular}{lcccc}
\hline & $\mathrm{n}$ & $\mathrm{M}(S D)$ & Median & Min - Max \\
\hline Future connectedness & 175 & $60.3(14.6)$ & 60.8 & $21.3-93$ \\
Future positivity & 171 & $3.55(.54)$ & 3.60 & $2-4.50$ \\
Future focus & 174 & $4.47(1.12)$ & 4.50 & $2-6.75$ \\
AUC & 163 & $.35(.27)$ & .26 & $.026-.96$ \\
Depression & 172 & $13(9.5)$ & 10 & $0-44$ \\
Future external details & 160 & $2.72(1.81)$ & 2.50 & $0-8$ \\
Future episodic & 160 & $0(1.95)$ & -.27 & $-2.74-6.59$ \\
$\begin{array}{l}\text { richness (composite) } \\
\text { Future temporal }\end{array}$ & 157 & $5.75(2.18)$ & 5.50 & $1-10$ \\
distance & 160 & $2.42(1.80)$ & 2.25 & $0-9.25$ \\
Past external details & 160 & $0(1.93)$ & .22 & $-4.30-4.90$ \\
$\begin{array}{l}\text { Past episodic richness } \\
\text { (composite) }\end{array}$ & & & & \\
\hline
\end{tabular}

Do EFT and future self-connectedness relate to one another? The extent to which participants felt connected to their future selves was significantly associated with aspects of the episodic detail they included in their future event narratives, although the size of this association was small (Ferguson, 2009). During the EFT task, participants who felt more connected to their future self provided future event narratives that were more episodic (partial $r(155)=.25, p=.002)$. These findings were unique to EFT. As can be seen from Table 3, 
future self-connectedness did not relate meaningfully to the episodic detail in participants' past event narratives.

\section{Do EFT and future self-connectedness relate to discounting behavior in}

adolescents? As expected, even after controlling for age, future self-connectedness correlated significantly with AUC (partial $\left.r_{(160)}=.35, p<.001\right)$, indicating that adolescents who felt more similar to their future selves were less likely to discount the value of future rewards. EFT also related meaningfully to discounting behavior. Participants who provided future event narratives that were more episodic were less likely to discount delayed rewards (partial $\left.r_{(145)}=.23, p=.005\right)$. This association continued to be statistically significant when variance due to performance on the same aspect of the EPT task had been controlled for (partial $\left.r_{(144)}=.28, p<.001\right)$.

A positive correlation was also observed between AUC and participant's self-reported clarity of EFT (partial $r_{(145)}=.20, p=.018$ ), when controlling for age and clarity of EPT. When controlling for age and temporal distance of EPT, AUC also correlated negatively with subjective temporal distance of the future event (partial $r_{(145)}=-.26, p<.001$ ), indicating that participants who felt their imagined future events were subjectively farther away discounted more than those who felt the events were subjectively closer. The relations between these phenomenological ratings of EFT and AUC were selective: clarity of EPT and subjective distance of past events were not significantly correlated with AUC. As can be seen from Table 3, discounting behavior was not associated with the episodic content of participant's past event narratives.

\section{Do EFT and future self-connectedness independently predict discounting}

behavior? To address questions about whether future self-connectedness and EFT have independent or overlapping relations with temporal discounting, hierarchical regression was 
Table 3. Partial correlations controlling for age showing the relationships between key variables.

\begin{tabular}{|c|c|c|c|c|c|c|}
\hline & 1 & 2 & 3 & 4 & 5 & 6 \\
\hline 1 Connectedness & - & & & & & \\
\hline 2 Future positivity & $\begin{array}{l}-.032 \\
(168)\end{array}$ & - & & & & \\
\hline 3 Future focus & $\begin{array}{l}-.15^{*} \\
(171)\end{array}$ & $\begin{array}{l}.49^{* *} \\
(167)\end{array}$ & - & & & \\
\hline $4 \mathrm{AUC}^{\Delta}$ & $\begin{array}{l}.35^{* *} \\
(160)\end{array}$ & $\begin{array}{l}-.006 \\
(156)\end{array}$ & $\begin{array}{l}-.016 \\
(159)\end{array}$ & - & & \\
\hline 5 Depression $^{\Delta}$ & $\begin{array}{l}-.21^{*} \\
(169)\end{array}$ & $\begin{array}{l}-.41^{* *} \\
(166)\end{array}$ & $\begin{array}{l}-.043 \\
(169)\end{array}$ & $\begin{array}{l}-.15 \\
(157)\end{array}$ & - & \\
\hline 6 Past episodic richness & $\begin{array}{c}.083 \\
(155)\end{array}$ & $\begin{array}{l}-.008 \\
(151)\end{array}$ & $\begin{array}{l}-.033 \\
(155)\end{array}$ & $\begin{array}{l}.009 \\
(145)\end{array}$ & $\begin{array}{l}-.098 \\
(153)\end{array}$ & - \\
\hline 7 Future episodic richness & $\begin{array}{c}.25^{*} \\
(155)\end{array}$ & $\begin{array}{l}.040 \\
(151)\end{array}$ & $\begin{array}{l}.049 \\
(155)\end{array}$ & $\begin{array}{l}.23^{*} \\
(145)\end{array}$ & $\begin{array}{l}-.065 \\
(153)\end{array}$ & $\begin{array}{l}.56^{* *} \\
(155)\end{array}$ \\
\hline $\begin{array}{l}* * p<.001 \\
* p<.05 \\
{ }^{*} \text { transformed variable }\end{array}$ & & & & & & \\
\hline \multicolumn{7}{|c|}{$\begin{array}{l}\text { used to identify whether EFT and future self-connectedness independently predicted variance } \\
\text { in participants' tendency to discount the future, while controlling for potentially relevant }\end{array}$} \\
\hline
\end{tabular}

First, a reduced linear model was set up including only the control variables as predictors of AUC. Control variables were age, external details for past and future events, EPT (episodic composite), and CES-D scores. This model explained $<1 \%$ of the variability in AUC (adjusted $R^{2}=.012$ ), thus falling below Ferguson's (2009) recommended minimum (practical) effect (RMPE) of $>.2$ for standardised $\beta$, and $>.04$ for adjusted $\mathrm{R}^{2}$. Age was the only significant predictor of AUC in this reduced model (see Table 4). Next, a reduced model was set up with the additional variable of future self-connectedness. This model explained $14 \%$ of the variance in AUC (adjusted $R^{2}=.14$ ). Age remained a significant predictor of AUC. Future self-connectedness was also a significant predictor of AUC. The addition of 
future self-connectedness in this model led to a significant increase in $R^{2}$ of $.13, F(1,141)=$ $22.3, p<.001$

A final full model was set up with the additional variable of EFT (episodic composite). This full model significantly predicted AUC, $R^{2}=.22, F(7,140)=5.53, p<.001$, and explained $18 \%$ of the variability in AUC scores (adjusted $R^{2}=.18$ ). The addition of EFT led to a significant increase in $R^{2}$ of $.041, F(1,140)=7.31, p=.008$. Both future selfconnectedness and EFT were significant predictors of AUC. Age remained a significant predictor of AUC in the full model. Future self-connectedness uniquely explained $9 \%\left(s r^{2}=\right.$ $.091)$ of the variance in AUC, while EFT and age explained 4\% $\left(s r^{2}=.041\right)$ and $3 \%\left(s r^{2}=\right.$ .034) of the variance respectively. Unexpectedly, past episodic detail was also a significant predictor of AUC in this final model, although as it explained only $2 \%$ of the variance in AUC, both it and age fall below Ferguson's (2009) minimum RMPE of .04.

Most importantly, both future self-connectedness and EFT independently predicted significant amounts of variance in temporal discounting when controlling for future external details, and after controlling for a number of other potentially confounding variables.

How do the measures of future orientation overlap? We examined relations between the various measures of future orientation included in the study. The relations between the measures (temporal discounting, EFT and future-self-connectedness) which our analyses had shown to be related, and measures of attitudes towards and engagement with the future, were of particular interest. To summarize, these latter measures were related to each other. Thus, more positive attitudes towards the future were associated with greater cognitive engagement with the future (partial $r_{(167)}=.49, p<.001$ ). Although a small, but negative association was found between future temporal focus and future self-connectedness (partial $\left.r_{(171)}=-.15, p=.045\right)$, positivity about and engagement with the future were unrelated to temporal discounting, or the episodic content of participants' EFT (see Table 3). 
Table 4. Hierarchical regression predicting temporal discounting (AUC)

\begin{tabular}{|c|c|c|c|c|c|c|}
\hline \multirow{2}{*}{ Variable } & \multicolumn{2}{|c|}{ Model 1} & \multicolumn{2}{|c|}{ Model 2} & \multicolumn{2}{|c|}{ Model 3} \\
\hline & $\mathrm{B}$ & $\beta$ & $\mathrm{B}$ & $\beta$ & $\mathrm{B}$ & $\beta$ \\
\hline Constant & .23 & & -.25 & & -.15 & \\
\hline Age & $.026^{*}$ & .20 & .026 & $.21^{*}$ & .025 & $.20^{*}$ \\
\hline EPT (episodic composite) & -.003 & -.021 & -.006 & -.052 & -.024 & $-.20^{*}$ \\
\hline Past external details ${ }^{\Delta}$ & -.018 & -.047 & -.023 & -.060 & -.025 & -.068 \\
\hline Future external details ${ }^{\Delta}$ & .032 & .082 & .044 & .11 & .054 & $.14^{*}$ \\
\hline Depression $^{\Delta}$ & -.025 & -.13 & -.010 & -.051 & -.011 & -.060 \\
\hline Future-self connectedness & & & .006 & $.37^{* *}$ & .005 & $.32^{* *}$ \\
\hline EFT (episodic composite) & & & & & .030 & $.26^{*}$ \\
\hline Adjusted $\mathrm{R}^{2}$ & .012 & & .14 & & .18 & \\
\hline $\mathrm{F}$ & 1.35 & & $5.01^{* *}$ & & $5.53^{* *}$ & \\
\hline$\Delta \mathrm{R}^{2}$ & .046 & & .13 & & .041 & \\
\hline$\Delta \mathrm{F}^{2}$ & 1.34 & & $22.3^{* *}$ & & $7.31^{*}$ & \\
\hline
\end{tabular}

We also examined correlations between the phenomenological ratings of EFT and the other future measures; these are reported in Table 5 (partial correlations controlling for age only). In summary, emotional intensity, mental time travel (MTT), and the extent to which participants reported pre-experiencing future emotions were all related both to positive attitudes towards the future and the amount of cognitive engagement with the future. Adolescents who reported more frequent engagement with the future also reported great clarity during EFT (partial $r_{(155)}=.24, p=.003$ ). Again, these relations were selective to EFT: the equivalent phenomenological ratings for EPT were not significantly related to attitudes to or cognitive engagement with the future. 
Table 5. Partial correlations controlling for age showing the relationships between key variables and the phenomenology of participants' EFT.

\begin{tabular}{|c|c|c|c|c|c|c|}
\hline & $\begin{array}{l}\text { Future } \\
\text { clarity }\end{array}$ & $\begin{array}{c}\text { Future } \\
\text { MTT }\end{array}$ & $\begin{array}{c}\text { Future } \\
\text { EmP }\end{array}$ & $\begin{array}{c}\text { Future } \\
\text { valence }\end{array}$ & $\begin{array}{l}\text { Future em. } \\
\text { intensity }^{\Delta}\end{array}$ & $\begin{array}{l}\text { Future } \\
\text { distance }\end{array}$ \\
\hline \multirow{2}{*}{ Connectedness } & .10 & -.033 & -.025 & .00 & .08 & -.15 \\
\hline & $(155)$ & (154) & (154) & $(152)$ & (154) & $(152)$ \\
\hline \multirow{2}{*}{ Future positivity } & .16 & $.24^{*}$ & $.26^{* *}$ & .16 & $.17^{*}$ & -.09 \\
\hline & $(151)$ & $(151)$ & (151) & $(150)$ & $(151)$ & $(150)$ \\
\hline \multirow{2}{*}{ Future focus } & $.24^{*}$ & $.26^{* *}$ & $.25^{*}$ & .10 & $.24^{*}$ & -.16 \\
\hline & (155) & (154) & (154) & $(152)$ & (154) & $(152)$ \\
\hline \multirow{2}{*}{$\mathrm{AUC}^{\Delta}$} & $.19^{*}$ & -.050 & -.086 & -.10 & -.061 & $-.26^{* *}$ \\
\hline & $(145)$ & $(145)$ & $(145)$ & (144) & $(145)$ & $(145)$ \\
\hline \multirow{2}{*}{ Depression $^{\Delta}$} & -.05 & -.08 & -.05 & $-.21^{*}$ & -.11 & .01 \\
\hline & (153) & (153) & (153) & $(152)$ & (153) & $(152)$ \\
\hline \multirow{2}{*}{ Past episodic richness } & $.33^{* *}$ & $.21^{*}$ & $.18^{*}$ & $.20^{*}$ & $.28^{* *}$ & .05 \\
\hline & (155) & (154) & (154) & (152) & (154) & $(152)$ \\
\hline \multirow{2}{*}{ Future episodic richness } & $.44^{* *}$ & $.25^{*}$ & $.23^{*}$ & $.17^{*}$ & $.25^{* *}$ & -.12 \\
\hline & (155) & (154) & (154) & $(152)$ & (154) & $(152)$ \\
\hline
\end{tabular}

Relations between future thinking and depression. CES-D scores were largely unrelated to participant's EFT and EPT, although there was an association between the valence of the participant's past and future thinking and depressive symptoms. Participants who scored higher on the CES-D were more likely to remember negative past events (partial $r_{(151)}=-.19$, $p=.02)$ and to imagine more negative future events (partial $r(152)=-.21, p=.01$ ). Although a negative association was observed between CES-D scores and AUC, suggesting higher depressive scores were associated with greater discounting behavior, this correlation was not significant (partial $\left.r_{(157)}=-.15, p=.057\right)$. 
Future self-connectedness was significantly correlated with CES-D scores (partial $r(169)=-.21, p=.006)$, indicating that adolescents who felt more connected to their future selves reported fewer depressive symptoms. Perhaps unsurprisingly, positive attitudes about the future were also associated with lower CES-D scores (partial $r_{(166)}=-.41, p<.001$ ). As is shown in Table 3, temporal focus was unrelated to depressive symptoms.

\section{Discussion}

Our study of future thinking used the widest range of tasks to date, and the results provide a number of new insights into future thinking in adolescents. First, although adolescents who felt more connected to their future self imagined the future (but not the past) with greater episodic richness, future self-connectedness and EFT independently predicted temporal discounting. These results suggest that measures of future self-connectedness and EFT tap into some of the same processes whilst, at the same time, predicting different aspects of the tendency to discount the future. Although this pattern of results accords with intuitions that EFT and future self-connectedness are related, it makes it unlikely that future selfconnectedness and EFT interventions decrease impulsive decisions because they both tap into identical underlying psychological processes.

A second important cluster of findings is that although adolescents' future time attitudes and future temporal focus were quite strongly associated, neither was found to be strongly related to future self-connectedness, temporal discounting, or the quality of EFT (as measured by the richness of episodic information participants produced). These results suggest that frequent cognitive engagement with the future and positive attitudes toward the future are not sufficient to make adolescents feel connected to their future selves or prioritize the future in decision making. Furthermore, they suggest that different measures of future thinking may tap into different aspects of what it means to be future-oriented. 
The third set of notable findings concerns the selective relationships observed between depressive symptoms and measures of future thinking. Adolescents with high depression scores felt significantly less connected to their future self and were more likely to imagine negative future events, but somewhat surprisingly in the light of the adult literature on depression and episodic thinking (Hallford, Austin, Takano, \& Raes, 2018), they did not generate less episodically rich future (or past) event narratives. Moreover, there was not a strong association observed between depression scores and temporal discounting.

\section{EFT, future self-connectedness and temporal discounting}

Temporal discounting was related to a number of other measures. Using a larger sample, this study replicated Bromberg et al.'s (2015) previous finding of an association between EFT capabilities and temporal discounting in adolescents. There was also an association between the clarity with which participants imagined future events and temporal discounting, as well as between how far away imagined future events felt and discounting. The latter finding is consistent with existing suggestions that temporal discounting is in part determined by the subjective distance of future time points, i.e., that there will be reduced discounting if future time points feel closer (Zauberman, Kim, Malkoc, \& Bettman, 2009) We also demonstrated for the first time that the association between future self-connectedness and temporal discounting previously observed in adults (see Urminsky, 2017) extends to an adolescent sample. Adolescence is conceived of as a period in which the sense of self can change dramatically (Habermas \& Bluck, 2000; Kroger, Martinussen, \& Marcia, 2010; Sebastian, Burnett, \& Blakemore, 2008), thus it is striking that the link between future selfconnectedness and delay discounting can be observed in this population. Adolescents' judgments in the self-connectedness task were meaningfully related to other variables, including depression, indicating that this simple task may be a useful one for use with this 
population, and future research could use this measure to explore more carefully the broader significance of self-connectedness in the adolescent period.

One of the study's aims was to address the question of whether the constructs of EFT and future self-connectedness overlap, and whether they independently predict variance in delay discounting in a sample of adolescents. To the best of our knowledge, this study is the first to report a correlation between EFT and future self-connectedness in any sample. However, it is not clear whether this reflects a causal relation between the two, and if so what the direction of causation may be. It seems plausible that the ability to richly imagine the future might assist in helping one feel connected to it (Blouin-Hudon \& Pychyl, 2017; Hershfield \& Bartels, 2018) and that EFT provides this rich imagination, but alternatively it could be that representing one's future self as stable and continuous provides a backdrop for more richly imagining the future. That future self-connectedness was correlated with adolescents' EFT, and that both independently predicted discounting, suggests that EFT and future self-connectedness are related, but distinct constructs. While EFT may be a mechanism that affects discounting rates through making salient the significance of future rewards (Boyer, 2008), it has been argued that conceiving of and having concern for one's future need not depend on EFT (Craver, Kwan, Steindam, \& Rosenbaum, 2014; Kwan et al., 2015), as evidenced by the fact that individuals with EFT deficits can use autobiographical knowledge to make future-oriented decisions. Individual differences in underlying beliefs about continuity in the self, and a tendency to feel responsible for (Bryan \& Hershfield, 2012), or to empathize with (Blouin-Hudon \& Pychyl, 2017), oneself in the future may account for the variance in temporal discounting that is uniquely explained by future self-connectedness.

That EFT and future self-connectedness independently predict temporal discounting in adolescents raises hope for new, more powerful interventions designed to improve adolescent decision making. Some recent interventions deliberately employ prompts used by 
EFT researchers but with the aim of increasing perceived self-continuity by increasing the vividness of the future self (see Kaplan, Reed, \& Jarmolowicz, 2016; Wu, Cheng, \& Chiou, 2017). For example, Blouin-Hudon and Pychyl (2017) showed that asking students to regularly listen to an audio file designed to prompt them to imagine, with episodic detail, their future self at the end of the semester reduced procrastination over academic tasks, by increasing empathy felt for the future self. However, at the same time, their manipulation produced increases in perceived self-continuity that were mediated by increases in the vividness of the future self. The results of Blouin-Hudon and Pychyl's study, and our own, suggest that (1) the relations between EFT and future self-connectedness are complex, and (2) interventions designed to reduce risky decision making in young adults might be made more effective by incorporating prompts to EFT as well as elements designed to increase perceived self-continuity.

There are two important caveats to our discussion thus far. First, the correlational nature of this study means that careful experimentation will be required to establish the nature and direction of the causal relationships amongst the variables EFT, future self-connectedness and temporal discounting. Second, because we aimed for a larger sample than did Bromberg et al (2015), we employed group-based testing and for this reason did not include a measure of intelligence. Although Bromberg and colleagues found that EFT predicted discounting when intelligence was controlled for, they also found that intelligence accounted for significant variance in discounting rates, in line with previous studies indicating a link between intelligence and discounting (Shamosh \& Gray, 2008; Steinberg et al., 2009). We suspect that the link between EFT and discounting that we report may not simply reflect the contribution of intelligence to both measures, because the relation was a selective one: EPT did not show a correlation with discounting despite a well-established association between episodic memory skills and intelligence in a variety of populations (e.g., Herlitz \& Yonker, 
2002; Leeson et al., 2010; Ratcliff, Thapar, \& McKoon, 2011). The relation between EFT and discounting held up controlling for episodic memory, as well as for depressive symptomatology. Nevertheless, future studies should include measures of intelligence. It may also be of interest to explore whether these associations persist were another measure of discounting to be used. For example, Bartels and Rips (2010) observed significant associations between a measure of future self-connectedness and participants' tendency to discount future rewards of gift cards and days off. Such discounting measures may have considerable potential for use with children and adolescents.

\section{Different measures of thinking about the future}

A striking finding from our study is that although we found associations between the richness of EFT, future self-connectedness and temporal discounting, these variables were not associated with measures of future time attitude and future temporal focus. However, these latter two variables were associated. Thus, there appear to be two clusters of measures purporting to reveal how adolescents think about the future. This pattern conflicts with the tendency to group a number of future-oriented constructs together under the rubric of "future orientation" (Steinberg et al., 2009). When referring to a future-oriented adolescent, it is typically meant that the adolescent thinks often, and feels positively, about the future (Robbins \& Bryan, 2004; Zimbardo, 1999). It may be tempting then to assume that this adolescent would also discount the future less, feel more connected to their future self, and imagine the future more vividly in EFT. We found no evidence to support this assumption. However, we note that, although EFT, as measured in terms of the amount of episodic information participants produced, was not related to attitudes towards and cognitive engagement with the future, some of the phenomenological ratings of EFT were correlated with these latter measures. Specifically, positivity towards the future and greater cognitive engagement with the future were related to the extent to which participants reported "pre- 
experiencing" future events/emotions and the intensity of the associated emotions (see also Arnold et al., 2011). The causal underpinnings of these associations are not clear: it could be that participants with a positive attitude towards and greater cognitive engagement with the future spend more time thinking about the future, leading to their future imaginings being more emotionally rich. An alternative possibility is that these associations reflect emotion regulatory style (D’Argembeau \& Van der Linden, 2006), with adolescents who are more likely to supress their emotions scoring lower on this set of measures.

Taken as a whole, the results of this study provide no evidence to justify the assumption that an adolescent with a positive attitude toward the future, and who thinks often about the future would also be considered 'future-oriented' if another measure, such as temporal discounting or future self-connectedness, were used. Researchers should therefore be clear which future-oriented construct they are specifically referring to when they refer to an individual as 'future-oriented'. On the basis of our previous discussion, it may be advisable for researchers to distinguish between measures which require adolescents to engage with a future self and those which merely assess their attitudes towards, or cognitive engagement with, the future.

Our results also have implications for debates about how best to measure attitudes towards, and engagement with, the future. The absence of association between future positivity, future temporal focus and impulsivity raises questions about whether these constructs should be measured separately in risk taking research. A critique of Zimbardo's Time Perspective Inventory (ZPTI, Zimbardo \& Boyd, 1999) is that it integrates constructs such as time attitudes and temporal focus with other individual differences factors, such as aspects of personality (Shipp et al., 2009). Using the ZPTI, future-oriented individuals have been shown to not only discount less (van den Bos et al., 2015), but to be less likely to engage in risk taking behaviors (Rothspan \& Read, 1996; Zimbardo, Keough, \& Boyd, 1997). 
However, when assessed separately in the present study, attitudes and focus failed to show an association with the discounting measure and have failed to relate to risk taking behaviors in previous research (McKay et al., 2012). This might suggest that other individual differences factors, as assessed by measures like the ZPTI, may be more important for predicting impulsivity and engagement in risk taking behaviors than attitudes and focus toward the future alone. Future work will be required to resolve the predictive utility of standalone measures of temporal attitudes and engagement compared to multiplex measures such as the ZPTI.

\section{Depressive symptomatology and thinking about the future}

A secondary aim of this study was to explore how depressive symptoms and adolescent future thinking relate to one another, given that depression has previously been linked with an impaired ability to generate episodically rich future events (Williams, 1994) and to discount the future (Jarmolowicz et al., 2014; Pulcu et al., 2014; Yoon et al., 2007). Although previous research with adults suggests that adults with symptoms of depression provide less episodic and more general descriptions of future events (e.g. Dickson \& Bates, 2006), we found no evidence for a link between EFT and depression in our adolescent sample. The absence of an association between EFT and depressive symptomatology may be due, in part, to the explicit nature of the EFT task used here, which might lack the sensitivity to identify overgeneral future thinking in adolescents in a non-clinical setting. Although such tasks have successfully shown EFT overgeneralization in clinically depressed adults (Roepke \& Seligman, 2016), the use of a task that involves explicit prompting to produce descriptions of specific one-off future events is not always sufficiently sensitive in a non-clinical population (Anderson, Boland, \& Garner, 2016; Raes, Hermans, Williams, \& Eelen, 2007). Future studies exploring impairments in EFT in adolescents with depressive symptoms might 
consider utilizing alternative methods, such as the sentence completion task (Raes et al., 2007), and also consider the emotional content of any cues (Anderson et al., 2016).

We also failed to find a significant relationship between depressive symptoms and delay discounting in our sample. This is not the first study to fail to find an association between depressive symptoms and temporal discounting in an adolescent sample (see Nigro, Cosenza, \& Ciccarelli, 2017). The inconsistent findings in the literature may be due to the existence of opposing effects: whereas depressive symptomatology in general may be associated with impaired EFT and thus lead to increased temporal discounting, anhedonia, which is an important component of depression, appears to be associated with decreased temporal discounting, due to decreased interest in the present (Lempert \& Pizzagalli, 2010). Thus, in any particular sample, the effects of anhedonia may mask any effects of more general depressive symptoms on discounting rates.

Our results did show that, consistent with the hypothesized link between depressive symptomatology and EFT, adolescents with depressive symptoms were more likely to imagine negative future events during the EFT task, supporting the work of a number of researchers interested in how depression impacts on future thinking (MacLeod, 2017; Miles, MacLeod, \& Pote, 2004). It is believed that negative events are more accessible to individuals experiencing depression and thus are more easily generated (MacLeod \& Byrne, 1996; MacLeod \& Cropley, 1995). The episodic simulation of positive future events likely serves to elevate mood and to challenge negative thoughts about what may lie in the future (Pictet, Coughtrey, Mathews, \& Holmes, 2011). Consequently, it is argued that the inability to envisage such positive future events might have a reciprocal relationship with depression. In other words, depressive thinking might lead to the imagination and anticipation of a bleak future, which would further serve to entrench low mood (Roepke \& Seligman, 2016). 
Adolescents with greater depressive symptoms also felt less connected to their future selves. This finding replicates an association recently found in adults and extends it to an adolescent sample (Sokol \& Eisenheim, 2016). Due to the correlational nature of this study, the direction of this relationship is unknown, although Sokol and Eisenheim (2016) propose that feeling disconnected from the future self could be both a cause and consequence of depression. The precise nature of the link between depressive symptomatology and future self-connectedness might be addressed in future research.

\section{Conclusion}

The results of our study have shown for the first time that EFT and future self-connectedness in adolescents are associated constructs, but that they independently predict discounting behavior. This pattern of results has implications for how we characterize the effects of earlier interventions to improve decision making and how we might design future interventions to reduce adolescents' tendency to take risks such as substance abuse, carrying a knife or having unprotected sex. The results also suggest that measures of adolescent future thinking may cluster, according to whether they necessitate consideration of the self in the future. Different measures of adolescent future thinking may assess very different things and researchers should exercise care when choosing how to measure future thinking in adolescence. In particular, our results suggest that positive attitudes toward the future and cognitive engagement with the future are not predictors of impulsive choice, as measured by the delay discounting task.

Future thinking is of profound importance during adolescence (Nurmi, 1991) and in order to help adolescents make good decisions about their future, it is important that we understand how to measure how they think about the future and which interventions are likely to be most effective in helping them make the best decisions. On the basis of our results, we suggest that increasing the vividness with which they consider a future self (to 
whom they feel closely connected) is likely to be an effective way of helping adolescents make better decisions about the future.

\section{References}

Addis, D. R., Sacchetti, D. C., Ally, B. A., Budson, A. E., \& Schacter, D. L. (2010). Episodic simulation of future events is impaired in mild Alzheimer's disease, 47, 2660-2671. http://doi.org/10.1016/j.neuropsychologia.2009.05.018.Episodic

Addis, D. R., Wong, A. T., \& Schacter, D. L. (2008). Age-related changes in the episodic simulation of future events. Psychological Science, 19, 33-41. http://doi.org/10.1111/j.14679280.2008.02043.x

Adelabu, D. H. (2008). Future time perspective, hope, and ethnic identity among African American adolescents. Urban Education, 43, 347-360. http://doi.org/10.1177/0042085907311806

Ainslie, G. (1974). Impulse control in pigeons. Journal of the Experimental Analysis of Behavior, 21, 485-9. http://doi.org/10.1901/jeab.1974.21-485

Anderson, R. J., Boland, J., \& Garner, S. R. (2016). Overgeneral past and future thinking in dysphoria: the role of emotional cues and cueing methodology. Memory, 24, 708-719. http://doi.org/10.1080/09658211.2015.1046134

Andretta, J. R., Worrell, F. C., \& Mello, Z. R. (2014). Predicting educational outcomes and psychological well-being in adolecents using time attitude profiles. Psychology in the Schools, 51, 434-451. http://doi.org/10.1002/pits.21762

Andretta, J. R., Worrell, F. C., Mello, Z. R., Dixson, D. D., \& Baik, S. H. (2013). Demographic group differences in adolescents' time attitudes. Journal of Adolescence, 36, 289-301. http://doi.org/10.1016/j.adolescence.2012.11.005

Apostolidis, T., Fieulaine, N., \& Soulé, F. (2006). Future time perspective as predictor of cannabis use: Exploring the role of substance perception among French adolescents. Addictive Behaviors, 
31, 2339-2343. http://doi.org/10.1016/j.addbeh.2006.03.008

Arnett, J. J. (1996). Sensation seeking, aggressiveness, and adolescent reckless behavior. Personality and Individual Differences, 20, 693-702. http://doi.org/10.1016/0191-8869(96)00027-X

Arnold, K. M., McDermott, K. B., \& Szpunar, K. K. (2011). Individual differences in time perspective predict autonoetic experience. Consciousness and Cognition, 20, 712-719. http://doi.org/10.1016/j.concog.2011.03.006

Atance, C. M., \& O’Neill, D. K. (2001). Episodic future thinking. Trends in Cognitive Sciences, 5, 533-539. http://doi.org/10.1016/S1364-6613(00)01804-0

Audrain-McGovern, J., Rodriguez, D., Epstein, L. H., Cuevas, J., Rodgers, K., \& Wileyto, E. P. (2009). Does delay discounting play an etiological role in smoking or is it a consequence of smoking? Drug and Alcohol Dependence, 103, 99-106. http://doi.org/10.1016/j.drugalcdep.2008.12.019

Banich, M. T., De, A., Vega, L., Andrews-Hanna, J. R., Seghete, K. M., Du, Y., \& Claus, E. D. (2013). Developmental trends and individual differences in brain systems involved in intertemporal choice during adolescence. http://doi.org/10.1037/a0031991

Bar, M., Bartlett, F. C., Noe, A., \& Schank, R. C. (2009). The proactive brain: Memory for predictions. Philosophical Transactions of the Royal Society of London. Series B, Biological Sciences, 364, 1235-43. http://doi.org/10.1098/rstb.2008.0310

Barnett, E., Spruijt-Metz, D., Unger, J. B., Rohrbach, L. A., Sun, P., \& Sussman, S. (2013). Bidirectional associations between future time perspective and substance use among continuation high-school students. Substance Use \& Misuse, 48, 574-580. http://doi.org/10.3109/10826084.2013.787092

Bartels, D. M., \& Rips, L. J. (2010). Psychological connectedness and intertemporal choice. Journal of Experimental Psychology: General, 139, 49-69. http://doi.org/10.1037/a0018062

Bartels, D. M., \& Urminsky, O. (2011). On intertemporal selfishness: How the perceived instability of 
identity underlies impatient consumption. Journal of Consumer Research, 38, 182-198.

http://doi.org/10.1086/658339

Baumann, A. A., \& Odum, A. L. (2012). Impulsivity, risk taking, and timing. Behavioural Processes, 90, 408-14. http://doi.org/10.1016/j.beproc.2012.04.005

Benoit, R. G., Gilbert, S. J., \& Burgess, P. W. (2011). A neural mechanism mediating the impact of episodic prospection on farsighted decisions. Journal of Neuroscience, 31, 6771-6779. http://doi.org/10.1523/JNEUROSCI.6559-10.2011

Bickel, W., \& Marsch, L. (2001). Toward a behavioral economic understanding of drug dependence: Delay counting process. Addiction, 96, 73-86. http://doi.org/10.1080/09652140020016978

Blouin-Hudon, E.-M. C., \& Pychyl, T. A. (2017). A mental imagery intervention to increase future self-continuity and reduce procrastination. Applied Psychology, 66, 326-352. http://doi.org/10.1111/apps.12088

Boyer, P. (2008). Evolutionary economics of mental time travel? Trends in Cognitive Sciences, 12, 219-224. http://doi.org/10.1016/j.tics.2008.03.003

Bromberg, U., Lobatcheva, M., \& Peters, J. (2017). Episodic future thinking reduces temporal discounting in healthy adolescents. PLOS ONE, 12, e0188079. http://doi.org/10.1371/journal.pone.0188079

Bromberg, U., Wiehler, A., \& Peters, J. (2015). Episodic future thinking is related to impulsive decision making in healthy adolescents. Child Development, 86, 1458-1468. http://doi.org/10.1111/cdev.12390

Bulley, A., Henry, J., \& Suddendorf, T. (2016). Prospection and the present moment: The role of episodic foresight in intertemporal choices between immediate and delayed rewards. Review of General Psychology, 20, 29-47. http://doi.org/10.1037/gpr0000061

Busseri, M. A., Malinowski, A., \& Choma, B. L. (2013). Are optimists oriented uniquely toward the future? Investigating dispositional optimism from a temporally-expanded perspective. Journal of 
Research in Personality, 47, 533-538. http://doi.org/10.1016/j.jrp.2013.04.015

Call, K. T., Riedel, A. A., Hein, K., McLoyd, V., Petersen, A., \& Kipke, M. (2002). Adolescent health and well-being in the twenty-first century: A global perspective. Journal of Research on Adolescence, 12, 69-98. http://doi.org/10.1111/1532-7795.00025

Chen, P., \& Vazsonyi, A. T. (2013). Future orientation, school contexts, and problem behaviors: A multilevel study. Journal of Youth and Adolescence, 42, 67-81. http://doi.org/10.1007/s10964$012-9785-4$

Chishima, Y., McKay, M. T., \& Cole, J. C. (2017). The generalizability of temporal focus profiles across cultures: A secondary analysis using data from Japan and the United Kingdom. Personality and Individual Differences, 111, 92-95. http://doi.org/10.1016/j.paid.2017.02.011

Chishima, Y., McKay, M. T., \& Murakami, T. (2017). The reliability and validity of the Temporal Focus Scale in young Japanese adults. Personality and Individual Differences, 119, 230-235. http://doi.org/10.1016/j.paid.2017.07.031

Christakou, A., Brammer, M., \& Rubia, K. (2011). Maturation of limbic corticostriatal activation and connectivity associated with developmental changes in temporal discounting. NeuroImage, 54 , 1344-1354. http://doi.org/10.1016/j.neuroimage.2010.08.067

Cosenza, M., \& Nigro, G. (2015). Wagering the future: Cognitive distortions, impulsivity, delay discounting, and time perspective in adolescent gambling. Journal of Adolescence, 45, 56-66. http://doi.org/10.1016/j.adolescence.2015.08.015

Craver, C. F., Kwan, D., Steindam, C., \& Rosenbaum, R. S. (2014). Individuals with episodic amnesia are not stuck in time. Neuropsychologia, 57, 191-195. http://doi.org/10.1016/J.NEUROPSYCHOLOGIA.2014.03.004

D’Argembeau, A., Ortoleva, C., Jumentier, S., \& Van Der Linden, M. (2010). Component processes underlying future thinking. Memory and Cognition, 38, 809-819. http://doi.org/10.3758/MC.38.6.809 
D’Argembeau, A., \& Van der Linden, M. (2006). Individual differences in the phenomenology of mental time travel: The effect of vivid visual imagery and emotion regulation strategies. Consciousness and Cognition, 15, 342-350. http://doi.org/10.1016/j.concog.2005.09.001

Daniel, T. O., Stanton, C. M., \& Epstein, L. H. (2013). The future is now: Comparing the effect of episodic future thinking on impulsivity in lean and obese individuals. Appetite, 71, 120-125. http://doi.org/10.1016/j.appet.2013.07.010

Daugherty, J. R., \& Brase, G. L. (2010). Taking time to be healthy: Predicting health behaviors with delay discounting and time perspective. Personality and Individual Differences, 48, 202-207. http://doi.org/10.1016/j.paid.2009.10.007

Dickson, J. M., \& Bates, G. W. (2006). Autobiographical memories and views of the future: In relation to dysphoria. International Journal of Psychology, 41, 107-116. http://doi.org/10.1080/00207590500188025

Ersner-Hershfield, H., Tess Garton, M., Ballard, K., Samanez-Larkin, G. R., \& Knutson, B. (2009). Don't stop thinking about tomorrow: Individual differences in future self-continuity account for saving Hal. Judgement and Decision Making, 4, 280-286.

http://doi.org/10.3851/IMP2701.Changes

Ersner-Hershfield, H., Wimmer, G. E., \& Knutson, B. (2009). Saving for the future self: Neural measures of future self-continuity predict temporal discounting. Social Cognitive and Affective Neuroscience, 4, 85-92. http://doi.org/10.1093/scan/nsn042

Ferguson, C. J. (2009). An effect size primer: A guide for clinicians and researchers. Professional Psychology: Research and Practice, 40, 532-538

Frederick, S., Loewenstein, G., \& O'donoghue, T. (2002). Time discounting and time preference: A critical review. Journal of Economic Literature. http://doi.org/10.1257/jel.40.2.351

Gilbert, D. T., \& Wilson, T. D. (2007). Prospection: Experiencing the future. Science, 317, 13511354. http://doi.org/10.1126/science.1144161 
Göllner, L. M., Ballhausen, N., Kliegel, M., \& Forstmeier, S. (2018). Delay of gratification, delay discounting and their associations with age, episodic future thinking, and future time perspective. Frontiers in Psychology, 8. http://doi.org/10.3389/fpsyg.2017.02304

Gott, C., \& Lah, S. (2014). Episodic future thinking in children compared to adolescents. Child Neuropsychology, 20, 625-640.

Green, L., Myerson, J., \& Ostaszewski, P. (1999). Discounting of delayed rewards across the life span: age differences in individual discounting functions. Behavioural Processes, 46, 89-96. http://psych.wustl.edu/lengreen/publications/Discounting of delayed rewards across the life span (1999).pdf

Guo, Y., Chen, Z., \& Feng, T. (2017). The effect of future time perspective on delay discounting is mediated by the gray matter volume of vmPFC. Neuropsychologia, 102, 229-236. http://doi.org/10.1016/j.neuropsychologia.2017.06.021

Habermas, T., \& Bluck, S. (2000). Getting a life: the emergence of the life story in adolescence. Psychological Bulletin, 126, 748-69. http://www.ncbi.nlm.nih.gov/pubmed/10989622

Hallford, D. J., Austin, D. W., Takano, K., \& Raes, F. (2018). Psychopathology and episodic future thinking: A systematic review and meta-analysis of specificity and episodic detail. Behaviour Research and Therapy, 102, 42-51. http://doi.org/10.1016/j.brat.2018.01.003

Herlitz, A., \& Yonker, J. E. (2002). Sex differences in episodic memory: The influence of intelligence. Journal of Clinical and Experimental Neuropsychology, 24, 107-114. http://doi.org/10.1076/jcen.24.1.107.970

Hershfield, H. E. (2011). Future self-continuity: How conceptions of the future self transform intertemporal choice. Annals of the New York Academy of Sciences, 1235, 30-43. http://doi.org/10.1111/j.1749-6632.2011.06201.x

Hershfield, H. E., \& Bartels, D. M. (2018). The future self. In The psychology of thinking about the future. (pp. 89-109). New York, NY, US: Guilford Press. 
Holman, E. A., \& Silver, R. C. (1998). Getting "stuck" in the past: Temporal orientation and coping with trauma. Journal of Personality and Social Psychology, 74, 1146-1163. http://doi.org/10.1037/0022-3514.74.5.1146

Jarmolowicz, D. P., Cherry, J. B. C., Reed, D. D., Bruce, J. M., Crespi, J. M., Lusk, J. L., \& Bruce, A. S. (2014). Robust relation between temporal discounting rates and body mass. Appetite, 78, 6367. http://doi.org/10.1016/j.appet.2014.02.013

Johnson, M. W., \& Bickel, W. K. (2008). An algorithm for identifying nonsystematic delaydiscounting data. Experimental and Clinical Psychopharmacology, 16, 264-274. http://doi.org/10.1037/1064-1297.16.3.264

Kaplan, B. A., Reed, D. D., \& Jarmolowicz, D. P. (2016). Effects of episodic future thinking on discounting: Personalized age-progressed pictures improve risky long-term health decisions. Journal of Applied Behavior Analysis, 49, 148-169. http://doi.org/10.1002/jaba.277

Kelly, L. M., Becker, S. J., \& Spirito, A. (2017). Parental monitoring protects against the effects of parent and adolescent depressed mood on adolescent drinking. Addictive Behaviors, 75, 7-11. http://doi.org/10.1016/j.addbeh.2017.06.011

Kerpelman, J. L., \& Mosher, L. S. (2004). Rural African American adolescents' future orientation: The importance of self-efficacy, control and responsibility, and identity development. Identity, 4, 187-208. http://doi.org/10.1207/s1532706xid0402_5

Khurana, A., Romer, D., Betancourt, L. M., \& Hurt, H. (2018). Modeling trajectories of sensation seeking and impulsivity dimensions from early to late adolescence: Universal trends or distinct sub-groups? Journal of Youth and Adolescence, 47 1992-2005. http://doi.org/10.1007/s10964018-0891-9

Kim-Spoon, J., McCullough, M. E., Bickel, W. K., Farley, J. P., \& Longo, G. S. (2015). Longitudinal associations among religiousness, delay discounting, and substance use initiation in early adolescence. Journal of Research on Adolescence: The Official Journal of the Society for 
Research on Adolescence, 25, 36-43. http://doi.org/10.1111/jora.12104

Kroger, J., Martinussen, M., \& Marcia, J. E. (2010). Identity status change during adolescence and young adulthood: A meta-analysis. Journal of Adolescence, 33, 683-698.

http://doi.org/10.1016/j.adolescence.2009.11.002

Kwan, D., Craver, C. F., Green, L., Myerson, J., Gao, F., Black, S. E., \& Rosenbaum, R. S. (2015). Cueing the personal future to reduce discounting in intertemporal choice: Is episodic prospection necessary? Hippocampus, 25, 432-443. http://doi.org/10.1002/hipo.22431

Kwan, D., Craver, C. F., Green, L., Myerson, J., \& Rosenbaum, R. S. (2013). Dissociations in future thinking following hippocampal damage: Evidence from discounting and time perspective in episodic amnesia. Journal of Experimental Psychology: General, 142, 1355-1369. http://doi.org/10.1037/a0034001

Lakdawalla, Z., Hankin, B. L., \& Mermelstein, R. (2007). Cognitive theories of depression in children and adolescents: A conceptual and quantitative review. Clinical Child and Family Psychology Review, 10, 1-24. http://doi.org/10.1007/s10567-006-0013-1

Leeson, V. C., Barnes, T. R. E., Harrison, M., Matheson, E., Harrison, I., Mutsatsa, S. H., ... Joyce, E. M. (2010). The relationship between IQ, memory, executive function, and processing speed in recent-onset psychosis: 1-year stability and clinical outcome. Schizophrenia Bulletin, 36, 400-9. http://doi.org/10.1093/schbul/sbn100

Lempert, K. M., \& Pizzagalli, D. A. (2010). Delay discounting and future-directed thinking in anhedonic individuals. Journal of Behavior Therapy and Experimental Psychiatry, 41, 258-264. http://doi.org/10.1016/j.jbtep.2010.02.003

Levine, B., Svoboda, E., Hay, J. F., Winocur, G., \& Moscovitch, M. (2002). Aging and autobiographical memory: Dissociating episodic from semantic retrieval. Psychology and Aging, 17, 677-689. http://doi.org/10.1037//0882-7974.17.4.677

Lindstrom Johnson, S., Blum, R. W., \& Cheng, T. L. (2014). Future orientation: A construct with 
implications for adolescent health and wellbeing. International Journal of Adolescent Medical Health, 26, 459-468. http://doi.org/10.1038/nmeth.2839.A

MacLeod, A. (2017). Prospection, well-being, and mental health. Oxford University Press. http://doi.org/10.1093/med:psych/9780198725046.001.0001

MacLeod, A. K., \& Byrne, A. (1996). Anxiety, depression, and the anticipation of future positive and negative experiences. Journal of Abnormal Psychology, 105, 286-289. http://doi.org/10.1037/0021-843X.105.2.286

MacLeod, A. K., \& Cropley, M. L. (1995). Depressive future-thinking: The role of valence and specificity. Cognitive Therapy and Research, 19, 35-50. http://doi.org/10.1007/BF02229675

Madden, G. J., \& Bickel, W. K. (2010). Impulsivity: The behavioral and neurological science of discounting. American Psychological Association. http://doi.org/10.1037/12069-000

McKay, M. T., Cole, J. C., \& Percy, A. (2017). Temporal focus clusters differ meaningfully in terms of anxiety and depressive symptomatology. Psychiatry Research, 256, 283-285. http://doi.org/10.1016/j.psychres.2017.06.061

McKay, M. T., Percy, A., \& Cole, J. C. (2013). Consideration of future consequences and alcohol use among Northern Irish adolescents. Journal of Substance Use, 18, 377-391. http://doi.org/10.3109/14659891.2012.685793

McKay, M. T., Percy, A., Cole, J. C., Worrell, F. C., \& Andretta, J. R. (2016). The relationship between time attitudes profiles and self-efficacy, sensation seeking, and alcohol use: An exploratory study. Personality and Individual Differences, 97, 203-209. http://doi.org/10.1016/j.paid.2016.03.060

McKay, M. T., Percy, A., Goudie, A. J., Sumnall, H. R., \& Cole, J. C. (2012). The Temporal Focus Scale: Factor structure and association with alcohol use in a sample of Northern Irish school children. Journal of Adolescence, 35, 1361-1368. http://doi.org/10.1016/j.adolescence.2012.05.006 
McKay, M. T., Perry, J. L., Cole, J. C., \& Worrell, F. C. (2018). What time is it? Temporal psychology measures relate differently to alcohol-related health outcomes. Addiction Research and Theory, 26, 20-27. http://doi.org/10.1080/16066359.2017.1309032

Mello, Z. R., \& Worrell, F. C. (2006). The relationship of time perspective to age, gender, and academic achievement among academically talented adolescents. Journal for the Education of the Gifted, 29, 271-289. http://doi.org/10.1177/016235320602900302

Mello, Z. R., Worrell, F. C., \& Andretta, J. R. (2009). Variation in how frequently adolescents think about the past, the present, and the future in relation to academic achievement. Diskurs Kindheits- Und Jugendforschung, 2, 173-183.

Michaelian, K., Klein, S. B., \& Szpunar, K. K. (2016). Seeing the future: Theoretical perspectives on future-oriented mental time travel. Seeing the future: Theoretical perspectives on future-oriented mental time travel. http://doi.org/http://dx.doi.org/10.1093/acprof:oso/9780190241537.001.0001

Miles, H., MacLeod, A. K., \& Pote, H. (2004). Retrospective and prospective cognitions in adolescents: anxiety, depression, and positive and negative affect. Journal of Adolescence, 27, 691-701. http://doi.org/10.1016/j.adolescence.2004.04.001

Mitchell, S. H., \& Wilson, V. B. (2010). The subjective value of delayed and probabilistic outcomes: Outcome size matters for gains but not for losses. Behavioural Processes, 83, 36-40. http://doi.org/10.1016/j.beproc.2009.09.003

Myerson, J., Green, L., \& Warusawitharana, M. (2001). Area under the curve as a measure of discounting. Journal of the Experimental Analysis of Behavior, 76, 235-43. http://doi.org/10.1901/jeab.2001.76-235

Nigro, G., Cosenza, M., \& Ciccarelli, M. (2017). The blurred future of adolescent gamblers: Impulsivity, time horizon, and emotional distress. Frontiers in Psychology, 8, 1-12. http://doi.org/10.3389/fpsyg.2017.00486

Nurmi, J. E. (1991). How do adolescents see their future? A review of the development of future 
orientation and planning. Developmental Review, 11, 1-59. http://doi.org/10.1016/02732297(91)90002-6

Oyserman, D., Bybee, D., \& Terry, K. (2006). Possible selves and academic outcomes: How and when possible selves impel action. Journal of Personality and Social Psychology, 91, 188-204. http://doi.org/10.1037/0022-3514.91.1.188

Oyserman, D., \& Markus, H. R. (1990). Possible selves and delinquency. Journal of Personality and Social Psychology, 59, 112-125. http://doi.org/10.1037/0022-3514.59.1.112

Peters, J., \& Büchel, C. (2010). Episodic future thinking reduces reward delay discounting through an enhancement of prefrontal-mediotemporal interactions. Neuron, 66, 138-148. http://doi.org/10.1016/j.neuron.2010.03.026

Pictet, A., Coughtrey, A. E., Mathews, A., \& Holmes, E. A. (2011). Fishing for happiness: The effects of generating positive imagery on mood and behaviour. Behaviour Research and Therapy, 49, 885-891. http://doi.org/10.1016/j.brat.2011.10.003

Pronin, E., Olivola, C. Y., \& Kennedy, K. A. (2008). Doing unto future selves as you would do unto others: Psychological distance and decision making. Personality and Social Psychology Bulletin, 34, 224-236. http://doi.org/10.1177/0146167207310023

Pulcu, E., Trotter, P. D., Thomas, E. J., McFarquhar, M., Juhasz, G., Sahakian, B. J., \& Elliott, R. (2014). Temporal discounting in major depressive disorder. Psychological Medicine, 44, 1825 1834. http://doi.org/10.1017/S0033291713002584

Radloff, L. S. (1977). The CES-D scale: A self-report depression scale for research in the general population. Applied Psychological Measurement, 1, 385-401. http://doi.org/10.1177/014662167700100306

Raes, F., Hermans, D., Williams, J. M. G., \& Eelen, P. (2007). A sentence completion procedure as an alternative to the autobiographical memory test for assessing overgeneral memory in nonclinical populations. Memory, 15, 495-507. http://doi.org/10.1080/09658210701390982 
Raffard, S., Esposito, F., Boulenger, J. P., \& Van der Linden, M. (2013). Impaired ability to imagine future pleasant events is associated with apathy in schizophrenia. Psychiatry Research, 209, 393-400. http://doi.org/10.1016/j.psychres.2013.04.016

Ratcliff, R., Thapar, A., \& McKoon, G. (2011). Effects of aging and IQ on item and associative memory. Journal of Experimental Psychology: General, 140, 464-487. http://doi.org/10.1037/a0023810

Robbins, R. N., \& Bryan, A. (2004). Relationships between future orientation, impulsive sensation seeking, and risk behavior among adjudicated adolescents. Journal of Adolescent Research, 19, 428-445. http://doi.org/10.1177/0743558403258860

Roepke, A. M., \& Seligman, M. E. P. (2016). Depression and prospection. British Journal of Clinical Psychology, 55, 23-48. http://doi.org/10.1111/bjc.12087

Rothspan, S., \& Read, S. J. (1996). Present versus future time perspective and HIV risk among heterosexual college students. Health Psychology: Official Journal of the Division of Health Psychology, American Psychological Association, 15, 131-4. Retrieved from http://www.ncbi.nlm.nih.gov/pubmed/8681921

Schacter, D. L., \& Addis, D. R. (2007). Constructive memory: The ghosts of past and future. Nature, 445, 27. http://doi.org/10.1038/445027a

Schacter, D. L., Addis, D. R., \& Buckner, R. L. (2008). Episodic simulation of future events: Concepts, data, and applications. Annals of the New York Academy of Sciences, 1124, 39-60. http://doi.org/10.1196/annals. 1440.001

Sebastian, C., Burnett, S., \& Blakemore, S.-J. (2008). Development of the self-concept during adolescence. Trends in Cognitive Sciences, 12, 441-446.

http://doi.org/10.1016/j.tics.2008.07.008

Seginer, R. (2003). Adolescent Future Orientation: An Integrated Cultural and Ecological Perspective. Online Readings in Psychology and Culture. International Association for Cross-Cultural 
Psychology, 6, 1-13. http://doi.org/10.9707/2307-0919.1056

Seginer, R. (2009). Future orientation: Developmental and ecological perspectives. Springer. http://doi.org/https://doi.org/http://psycnet.apa.org.ezprimo1.idc.ac.i1/doi/10.1007/b106810

Shamosh, N. A., \& Gray, J. R. (2008). Delay discounting and intelligence: A meta-analysis. Intelligence, 36, 289-305. http://doi.org/10.1016/j.intell.2007.09.004

Shipp, A. J., Edwards, J. R., \& Lambert, L. S. (2009). Conceptualization and measurement of temporal focus: The subjective experience of the past, present, and future. Organizational Behavior and Human Decision Processes, 110, 1-22. http://doi.org/10.1016/j.obhdp.2009.05.001

So, S., Voisin, D. R., Burnside, A., \& Gaylord-Harden, N. K. (2016). Future orientation and health related factors among African American adolescents. Children and Youth Services Review, 61, 15-21. http://doi.org/10.1016/j.childyouth.2015.11.026

Sokol, Y., \& Eisenheim, E. (2016). The Relationship Between Continuous Identity Disturbances, Negative Mood, and Suicidal Ideation. The Primary Care Companion For CNS Disorders, 18(1). http://doi.org/10.4088/PCC.15m01824

Steinberg, L. (2004). Risk taking in adolescence: What changes, and why? Annals of the New York Academy of Sciences, 1021, 51-58. http://doi.org/10.1196/annals.1308.005

Steinberg, L., Graham, S., O’Brien, L., O’Brien, L., Woolard, J., Cauffman, E., \& Banich, M. (2009). Age differences in future orientation and delay discounting. Child Development, 80, 28-44. http://doi.org/10.1111/j.1467-8624.2008.01244.x

Stoddard, S. A., Zimmerman, M. A., \& Bauermeister, J. A. (2011). Thinking about the future as a way to succeed in the present: A longitudinal study of future orientation and violent behaviors among African American youth. American Journal of Community Psychology, 48, 238-246. http://doi.org/10.1007/s10464-010-9383-0

Suddendorf, T., \& Busby, J. (2005). Making decisions with the future in mind: Developmental and 
comparative identification of mental time travel. Learning and Motivation, 36, 110-125.

http://doi.org/10.1016/j.lmot.2005.02.010

Suddendorf, T., \& Corballis, M. C. (2007). The evolution of foresight: What is mental time travel, and is it unique to humans? Behavioral and Brain Sciences, 30, 1-34.

http://doi.org/10.1017/S0140525X07001975

Szpunar, K. K. (2010). Evidence for an implicit influence of memory on future thinking. Memory and Cognition, 38, 531-540. http://doi.org/10.3758/MC.38.5.531

Taylor, S. E., Pham, L. B., Rivkin, I. D., \& Armor, D. A. (1998). Harnessing the imagination: Mental simulation, self-regulation, and coping. American Psychologist, 53, 429-439. http://doi.org/10.1037/0003-066X.53.4.429

Tulving, E. (2005). Episodic Memory and Autonoesis: Uniquely Human? In The Missing Link in Cognition. Oxford University Press. http://doi.org/10.1093/acprof:oso/9780195161564.003.0001

Urminsky, O. (2017). The role of psychological connectedness to the future self in decisions over time. Current Directions in Psychological Science, 26, 34-39. http://doi.org/10.1177/0963721416668810

van den Bos, W., Rodriguez, C. A., Schweitzer, J. B., \& McClure, S. M. (2015). Adolescent impatience decreases with increased frontostriatal connectivity. Proceedings of the National Academy of Sciences, 112, E3765-E3774. http://doi.org/10.1073/pnas.1423095112

van Gelder, J. L., Hershfield, H. E., \& Nordgren, L. F. (2013). Vividness of the future self predicts delinquency. Psychological Science, 24, 974-980. http://doi.org/10.1177/0956797612465197

Wang, Q., Capous, D., Koh, J. B. K., \& Hou, Y. (2014). Past and future episodic thinking in middle childhood. Journal of Cognition and Development, 15, 625-643. http://doi.org/10.1080/15248372.2013.784977

Williams, J. M. G., Barnhofer, T., Crane, C., Herman, D., Raes, F., Watkins, E., \& Dalgleish, T. (2007). Autobiographical memory specificity and emotional disorder. Psychological Bulletin, 
133, 122-148. http://doi.org/10.1037/0033-2909.133.1.122

Williams, J. M. G., Ellis, N. C., Tyers, C., Healy, H., Rose, G., \& Macleod, A. K. (1996). The specificity of autobiographical memory and imageability of the future. Memory \& Cognition, 24, 116-125. http://doi.org/10.3758/BF03197278

Willoughby, K. A., Desrocher, M., Levine, B., \& Rovet, J. F. (2012). Episodic and semantic autobiographical memory and everyday memory during late childhood and early adolescence. Frontiers in Psychology, 3, 1-15. http://doi.org/10.3389/fpsyg.2012.00053

Wilson, V. B., Mitchell, S. H., Musser, E. D., Schmitt, C. F., \& Nigg, J. T. (2011). Delay discounting of reward in ADHD: application in young children. Journal of Child Psychology and Psychiatry, 52, 256-264. http://doi.org/10.1111/j.1469-7610.2010.02347.x

Worrell, F. C., Mello, Z. R., \& Buhl, M. (2007). The Adolescent Time Inventory. Unpublished scale.

Wu, W. H., Cheng, W., \& Chiou, W. Bin. (2017). Episodic future thinking about the ideal self induces lower discounting, leading to a decreased tendency toward cheating. Frontiers in Psychology, 8, 1-9. http://doi.org/10.3389/fpsyg.2017.00287

Yang, L., Jia, C.-X., \& Qin, P. (2015). Reliability and validity of the Center for Epidemiologic Studies Depression Scale (CES-D) among suicide attempters and comparison residents in rural China. BMC Psychiatry, 15, 76. http://doi.org/10.1186/s12888-015-0458-1

Zauberman, G., Kim, B. K., Malkoc, S. A., \& Bettman, J. R. (2009). Discounting Time and Time Discounting: Subjective Time Perception and Intertemporal Preferences. Journal of Marketing Research, 46, 543-556. http://doi.org/10.1509/jmkr.46.4.543

Zimbardo, P. G., \& Boyd, J. N. (1999). Putting time in perspective: A valid, reliable individualdifferences metric. Journal of Personality and Social Psychology, 77, 1271-1288. http://doi.org/10.1037/0022-3514.77.6.1271

Zimbardo, P. G., Keough, K. A., \& Boyd, J. N. (1997). Present time perspective as a predictor of risky driving. Personality and Individual Differences, 23, 1007-1023. 
http://doi.org/10.1016/S0191-8869(97)00113-X 